\title{
Questões em torno da transferência de custódia de documentos entre arquivos públicos
}

\author{
Cuestiones en torno a la transferencia de la custodia de los documentos entre archivos públicos
}

Issues around the transfer of records custody among public archives

\author{
Sonia TROITIÑO \\ Departamento de Ciência da Informação, Faculdade de Filosofia e Ciências (UNESP-Marília), \\ Cidade Universitária Marília SP, Brasil, smtr@marilia.unesp.br
}

\begin{abstract}
Resumen
El presente trabajo busca discutir las diversas formas y condiciones de incorporación de acervos procedentes del poder judiciario por órganos del poder ejecutivo. Para eso, utilizaremos para conducir el debate, la historia de custodia del archivo procedente del Juízo de Órfãos de São Paulo, instancia de la justicia brasileña existente entre los siglos $\mathrm{XVI}$ y $\mathrm{XX}$, que actualmente se encuentra fragmentada en varias instituciones, bajo distintas denominaciones. De la misma manera, otros archivos originarios de órganos de la justicia, sufrieron semejante proceso de transferencia de guardia. Sin embargo, ese tipo de situación no se restringe a épocas pasadas, en los días actuales, mismo con normas y orientaciones legalmente establecidas para la implantación de programas de gestión documental, todavía es posible encontrar a menudo la adición de procedimientos similares de incorporación de acervos. Procuraremos aquí establecer un paralelo entre esos momentos y la legislación archivística brasileña en vigor.
\end{abstract}

Palabras clave: Historia custodial. Archivos judiciales. Transfencia archivística. Juízo de Órfãos de São Paulo.

\section{Introdução}

Pretendemos utilizar este espaço para iniciar a discussão sobre a transferência de acervos entre diferentes instâncias do poder público. $\mathrm{Na}$ atualidade, o debate sobre a racionalização administrativa propulsiona a adoção de critérios adequados que visem a garantir uma gestão documental eficaz. Nesse contexto, muitas vezes, a transmissão da custódia de arquivos se mostra como uma possibilidade de solução de problemas referentes à preservação e manutenção de documentos. Se hoje a transferência da guarda se apresenta de modo institucionalizado, através de termos formais que assegurem o gerenciamento e manutenção de arquivos, sem que isso implique necessariamente ausência de responsabilidade legal sobre os documentos, antigamente os processos de transmissão de

\begin{abstract}
This paper discusses the different forms and conditions of incorporating collections from the judiciary by executive bodies. For such, we use the custodial history of the Juízo de Órfãos de São Paulo archives as a reference. An instance of the Brazilian justice between the 16th and 20th centuries, the Juízo de Órfãos de São Paulo is currently fragmented in several institutions of custody and under different denominations. Similarly, other archives from judiciary bodies underwent similar processes for custody transfer. However, this type of situation is not restricted to the past: nowadays, even under legally established norms and guidelines for the implementation of document management programs, it is still possible to find, recurrently, the adoption of similar procedures for the incorporation of collections. We therefore intend to establish a parallel between these two moments and the Brazilian archival legislation in force.
\end{abstract}

Keywords: Custodial history. Court archives. Records transfer. Juízo de Órfãos de São Paulo.

custódia entre diferentes instituições acompanhavam a responsabilidade legal sobre a documentação.

Para este debate, utilizaremos como fio condutor a história custodial do arquivo procedente do Juízo de Órfãos de São Paulo, órgão da justiça brasileira existente entre os séc. XVI e XX, que atualmente se encontra fragmentado em várias instituições de guarda, sobre diferentes denominações. Os arquivos provenientes dessa já extinta instituição vêm sofrendo, há mais de um século, diferentes processos de recolhimento, ocasionando, em consequência, a fragmentação do fundo.

O presente trabalho procura discutir as diversas formas e condições de incorporação de acervos oriundos do judiciário por órgãos do poder exe- 
cutivo, fazendo um paralelo entre os diferentes momentos da transmissão de um mesmo acervo e a legislação arquivística em vigor. Como este é um projeto em fase inicial, procuraremos aqui fazer a apresentação de dados preliminares e algumas considerações sobre aspectos arquivísticos relacionados à transmissão da guarda de fundos arquivísticos e as possíveis consequências desse processo, desde o ponto de vista da arquivologia.

\section{Trajetória custodial do Arquivo do Juízo de Órfãos de São Paulo}

O documento jurídico mais antigo existente em São Paulo, Brasil, que temos notícia é o inventário do sapateiro Damião Simões, que se encontra no Arquivo Público do Estado de São Paulo (APESP). Iniciado em 1578, só teve seus autos conclusos em 1602 quando o menor envolvido, também de nome Damião Simões, alcançara a idade necessária para se reger, assumindo assim, através de carta de emancipação, a posse de seus bens, até então administrados pelo curador legalmente estabelecido (APESP, 1920).

Além de esse ser o processo judicial mais antigo do estado, é também o documento mais antigo do próprio Arquivo Público do Estado de São Paulo. No entanto, a ele juntam-se outras centenas de caixas-arquivo. Até início de 2010, estimava-se a existência de pelo menos 1.300 caixas arquivo contendo milhares de processos judiciais, tantos cíveis quanto criminais, provenientes de diversas varas, comarcas e instâncias da Justiça. Entre as instituições existentes destacavam-se os Juízos Ordinário, Resíduos, Defuntos e Ausentes, Municipal, Juiz de Paz, Juízo Municipal, Juízo de Direito de várias localidades paulistas, como também documentação oriunda do Tribunal de Justiça de São Paulo.

Gostaríamos de ressaltar que, apesar de haver uma grande variedade de processos cíveis e criminais no APESP, não significa que essa documentação tenha sido incorporada na mesma época ao seu acervo. Cada um desses segmentos documentais provindos do judiciário possui sua história arquivística própria, com características específicas de origem, trajetória e guarda anterior.

Neste artigo, nos limitaremos a discorrer sobre os documentos provenientes das atividades desempenhadas pelo Juízo de Órfãos da Comarca de São Paulo que se encontram em posse do APESP. São cerca de 7.600 processos, distribuídos atualmente em 449 caixas-arquivo, abarcando o período compreendido entre os anos 1578 e 1926 . Estes são dados relativos ao ano de 2009 do fundo custodiado pelo APESP, o que não significa necessariamente a não existência de documentação procedente da mesma instância da justiça em outras unidades de informação.

É possível, também, encontrar uma grande quantidade de processos orfanológicos da comarca da capital no Arquivo do Tribunal de Justiça de São Paulo. No entanto, esses processos devem ser localizados em meio à documentação identificada como Vara da Família, órgão que sucedeu e assumiu diversas das funções do Juízo de Órfãos no Estado de São Paulo. Alguns processos orfanológicos pontuais também podem ser vistos expostos no Museu do Tribunal de Justiça, porém inseridos em âmbito museológico —o que, consequentemente, afeta diretamente a percepção de significantes e significados de aspectos de produção documental, funções e atividades do órgão produtor, por estes haverem sido alterados em relação aos seus valores arquivísticos.

Pouco se conhece sobre as primeiras incorporações de documentação provenientes do Juízo de Órfãos de São Paulo ao arquivo do executivo estadual e, infelizmente, não foram encontrados registros de entrada da documentação nos relatórios da instituição. Contudo, é de conhecimento que, em 1899, uma lei paulista, a de n. ${ }^{\circ} 666$, de 6 de setembro, determinou que toda a documentação anterior ao século XIX pertencente aos cartórios do judicial fosse transferida para o Arquivo do Estado de São Paulo (São Paulo, Decreto 666/1899):

Artigo $1^{\circ}$ - Serão removidos dos cartórios dos escrivães do judicial, oficiais de registros e tabeliães de notas, para o arquivo público do Estado, todos os papeis, autos e livros anteriores ao século XIX.

Esta é considerada uma das explicações mais plausíveis para o fato de haver grande quantidade de documentação proveniente do poder judiciário depositada junto a acervos do poder executivo -ainda que o recolhimento desses documentos, conforme determinava a lei, não tenha sido efetivamente realizado em sua totalidade.

Não existem documentos que registrem com exatidão as datas de incorporação desses acervos. Contudo, através dos relatórios do arquivo, encontramos menção da primeira listagem de inventários post-mortem do Juízo dos Órfãos de São Paulo datar de 1904. Dessa maneira, é possível estabelecer uma provável data para a primeira leva de incorporação desse acervo, entre os anos de 1900 e 1904. 
Algum tempo depois da incorporação do arquivo do Juízo de Órfãos, iniciaram-se os trabalhos de transcrição da documentação e em 1920 é lançado o primeiro volume da coleção Inventários e Testamentos (APESP, 1920-1999), com o intuito de divulgar transcrições de parte dessa documentação, o que em muito facilitou o acesso ao seu conteúdo. É justamente na introdução dessa publicação que pode ser encontrado o indício mais concreto da origem dessa documentação, ao fazer referência à transferência dos documentos pertencentes ao $1^{\circ}$ Cartório de Órfãos da Capital ao arquivo público. Informa, também, que esse acervo não pode ser transferido integralmente e sobre a completa perda dos inventários pertencentes ao $2^{\circ}$ Cartório de Órfãos da Capital (APESP, 1920).

Realmente, ao analisarmos a documentação orfanológica custodiada pelo APESP, verificamos que considerável parcela desse acervo foi produzida pelas $1^{\mathrm{a}}$ e $2^{\mathrm{a}}$ Varas de Órfãos, Ausentes e Anexos, ambas alocadas no $1^{\circ}$ Ofício da Capital, em finais do século XIX. Ainda que a documentação do Juízo dos Órfãos produzida anteriormente não fosse decorrente da $1^{\mathrm{a}}$ ou da $2^{a}$ vara -até mesmo porque no período anterior ao XIX, não havia sido montada tal estrutura burocrática- manteve-se reunida no mesmo cartório por acumulação.

Da implantação do judiciário brasileiro até a década de 1830, as questões orfanológicas mantiveram um juízo privativo exclusivo para seu atendimento, quando a Lei de 3 de Novembro de 1830 determina a extinção da Provedoria de Ausente, assim como seu regimento, leis e provisões, passando sua administração e arrecadação pertencer ao Juízo dos Órfãos. Essa mesma lei determinou que o cartório fosse transferido ao escrivão dos órfãos (Suzano, 1854, p. 91). A partir de então, as atribuições do Ramo de Defuntos e Ausentes, anteriormente órgão do Juízo da Provedoria, passa ser também de competência do Juízo de Órfãos da capital (Ramalho, 1874; Poveda, 2007).

Em 1891, a Lei Paulista $n^{\circ} 18$, de 21 de novembro, reorganiza a Justiça do Estado de São Paulo e determinava que em cada comarca do estado houvesse um juiz de direito, com exceção da capital, onde foram criadas cinco varas: cível, criminal, órfãos e ausentes, feitos da fazenda e provedoria. Com a reestruturação administrativa da justiça paulista, a antiga composição cartorária do Juízo dos Órfãos e seu respectivo arquivo foram incorporados à nova vara, ficando o Tribunal de Justiça de São Paulo responsável em última instância pela guarda da documentação (Poveda, 2007).
Em 1892, a Lei 80, de 25 de agosto, amplia a estrutura do Juízo de Órfãos criando uma segunda vara na Capital (São Paulo, Lei 80/1892):

Art. $1^{\circ}$ - Na lei $n^{\circ} 18$ de 21 de novembro de 1891, são feitas as alterações seguintes: $\S 1^{\circ}$ Ficam extintos os termos judiciários, passando cada um dos que existem atualmente a constituir comarca; $\S 2^{\circ}$ As comarcas que foram criadas para o futuro deverão conter pelo menos duzentos juízes de fato e uma população não inferior a dez mil almas; $\S 3^{\circ}$ São suprimidos os juízes de paz substitutos e os tribunais correcionais cujas funções ficam pertencentes aos juízes de direito; $\S 4^{\circ}$ Haverá em cada comarca um juiz de direito exceto: a) $\mathrm{Na}$ capital, onde haverá dois, com jurisdição cumulativa com o civil e comercial; dois privativos da vara de órfãos e ausentes; e um das varas dos feitos e da fazenda do Estado e da Provedoria, sendo a jurisdição criminal cumulativamente exercida por todos.

$\mathrm{O}$ artigo $2^{\circ}$, do Decreto $\mathrm{n}^{\circ} 3432$, de 31 de dezembro de 1921, regulamenta a boa execução da lei $n^{\circ} 1.759$, de 17 de novembro do mesmo ano, que reforma a organização judiciária do Estado de São Paulo, e mantém duas Varas de Órfãos e Ausentes na Capital.

Alguns estados brasileiros mantêm, ainda hoje, em sua estrutura judiciária varas denominadas "de órfãos". Em São Paulo, de acordo com o Decreto-Lei 11.058, art. 25, de 26 de abril de 1940 , as Varas de Órfãos e Ausentes foram extintas e criadas as de Família e Sucessões, ficando esta última responsável pelas atribuições e competências do Juízo de Órfãos e herdando sua estrutura administrativa (São Paulo, Decreto-lei 11.058/1940):

Art. $25^{\circ}-$ As atuais varas de Órfãos, Ausente, Provedoria, e Contencioso de Casamentos, passam a denominar-se vara da Família e Sucessões; Artigo $26^{\circ}$ - Volta para a jurisdição dos juízes do cível os inventários e partilhas que não houver testamentos ou interessados incapazes.

Anteriormente mencionamos que a documentação pertencente ao fundo Juízo dos Órfãos de São Paulo não foi incorporada em um único recolhimento - pautados no fato do primeiro instrumento de pesquisa referente ao Juízo dos Órfãos ser datado de 1904, enquanto que a data do último documento encontrado no fundo corresponder ao ano de 1926. Assim, revela-se coerente pensar em momentos de recolhimento distintos, dentro de uma política direcionada para a guarda de documentos do judiciário pelo executivo. Infelizmente, também não foram encontradas, nos relatórios de época, menções à incorporação desse outro conjunto documental ao acervo do APESP.

O volume do acervo orfanológico, custodiado pelo arquivo permanente do executivo paulista, 
foi ampliado quando, em março de 2010, um termo de cooperação, firmado entre o Tribunal de Justiça do Estado de São Paulo (TJSP) e o governo estadual paulista, transferiu a responsabilidade da guarda de processos judiciais anteriores a 1890 para o Arquivo Público do Estado de São Paulo (APESP), prevendo a preservação e digitalização desses documentos.

Segundo excerto publicado em $1^{\circ}$ de abril de 2010 no Diário Oficial do Poder Executivo de São Paulo, o acordo firmou-se nos seguintes termos (DOSP, 2010):

Partícipe: o Poder Judiciário, por intermédio do Tribunal de Justiça, e o Poder Executivo, por intermédio da Casa Civil, atuando por meio da Unidade do Arquivo Público do Estado - Objeto: a conjugação de esforços entre os partícipes objetivando a transferência da guarda, a preservação e o restauro de autos de processos judiciais - Recursos: o custeio das despesas decorrentes do termo será suportado pelos partícipes na medida de suas atribuições, em conformidade com as respectivas dotações, inexistindo repasse de recursos entre si em razão do presente ajuste - Vigência: o prazo de vigência do termo é de 5 anos, contados da data de sua assinatura. - Data de assinatura: 29-32010.

Como pode ser observado, o convênio estabelecido é bastante amplo, abrangendo, de forma genérica, todo o processo judicial sob a guarda do Tribunal de Justiça de São Paulo, independentemente do fórum ou cartório de origem, ou seja, independentemente de sua procedência.

\section{Reflexões em torno da legislação}

Em teoria, toda essa documentação orfanológica pertence a outra esfera de poder que não a do executivo e, considerando a existência de um arquivo central da Justiça, não deveria misturar-se à proveniente do governo do estado.

De acordo com a Lei Federal $n^{\circ} 8.159$, de 8 de janeiro de 1991, a qual dispõe sobre a política nacional de arquivos públicos e privados, o artigo $7^{\circ}$, do cap. II define que

Os arquivos públicos são os conjuntos de documentos produzidos e recebidos, no exercício de suas atividades, por órgãos públicos de âmbito federal, estadual, do Distrito Federal e municipal em decorrência de suas funções administrativas, legislativas e judiciárias

Portanto, acervos resultantes de atividades cotidianas e capazes de evidenciar as ações e situações tratadas pela entidade a qual representam. Assim sendo, para além de aspectos teóricos da arquivologia, consolidou-se legalmente a definição a ser adotada para o reconhecimento do caráter público de arquivos, em oposição aos arquivos de caráter privado. $O$ Capítulo IV da mesma lei, ao tratar da organização e administração de instituições públicas, estabelece que:

Art. 17 A administração da documentação pública ou de caráter público compete às instituições arquivísticas federais, estaduais, do Distrito Federal e municipais.

$\S 1^{\circ}$ São Arquivos Federais o Arquivo Nacional do Poder Executivo, e os arquivos do Poder Legislativo e do Poder Judiciário. São considerados, também, do Poder Executivo os arquivos do Ministério da Marinha, do Ministério das Relações Exteriores, do Ministério do Exército e do Ministério da Aeronáutica.

$\S 2^{\circ}$ São Arquivos Estaduais o arquivo do Poder Executivo, o arquivo do Poder Legislativo e o arquivo do Poder Judiciário.

$\S 3^{\circ}$ São Arquivos do Distrito Federal o arquivo do Poder Executivo, o arquivo do Poder Legislativo e o arquivo do Poder Judiciário.

$\S 4^{\circ}$ São Arquivos Municipais o arquivo do Poder Executivo e o arquivo do Poder Legislativo.

$\S 5^{\circ}$ Os arquivos públicos dos Territórios são organizados de acordo com sua estrutura políticojurídica. [...]

Art. 19 Competem aos arquivos do Poder Legislativo Federal a gestão e o recolhimento dos documentos produzidos e recebidos pelo Poder Legislativo Federal no exercício de suas funções, bem como preservar e facultar o acesso aos documentos sob sua guarda.

Art. 20 Competem aos arquivos do Poder Judiciário Federal a gestão e o recolhimento dos documentos produzidos e recebidos pelo Poder Judiciário Federal no exercício de suas funções, tramitados em juízo e oriundos de cartórios e secretarias, bem como preservar e facultar o acesso aos documentos sob sua guarda.

O texto da lei deixa claras as competências de cada instância de poder sobre os arquivos provenientes de suas atividades enquanto instituições públicas. Porém, por outro lado, a lei delega aos estados da federação que estipulem os critérios a serem adotados na organização e acessibilidade de seus documentos, como pode ser verificado no seguinte artigo do ainda Capítulo IV:

Art. 21 Legislação Estadual, do Distrito Federal e municipal definirá os critérios de organização e vinculação dos arquivos estaduais e municipais, bem como a gestão e o acesso aos documentos, observado o disposto na Constituição Federal, e nesta Lei.

O Decreto Estadual Paulista $n^{\circ} 48.897$, de 27 de agosto de 2004, ao dispor sobre os Arquivos Públicos, os documentos de arquivo e sua gestão, os Planos de Classificação e a Tabela de Temporalidade de Documentos da Administra- 
ção Pública do Estado de São Paulo define normas para a avaliação, guarda e eliminação de documentos de arquivo, similarmente à Lei Federal 8159/91:

Artigo $5^{\circ}$ - Os documentos de arquivo, em razão de seus valores, podem ter guarda temporária ou guarda permanente, observados os seguintes critérios:

I - são documentos de guarda temporária aqueles que, esgotados os prazos de guarda na unidade produtora ou nas unidades que tenham atribuições de arquivo nas Secretarias de Estado, ou na Seção Técnica de Arquivo Intermediário, do Arquivo do Estado, podem ser eliminados sem prejuízo para a coletividade ou memória da Administração Pública Estadual;

II - são documentos de guarda permanente aqueles que, esgotados os prazos de guarda previstos no inciso I deste artigo, devem ser preservados, por força das informações neles contidas, para a eficácia da ação administrativa, como prova, garantia de direitos ou fonte de pesquisa.

Artigo $6^{\circ}$ - As unidades de guarda dos documentos produzidos em cada Secretaria de Estado são as previstas na estrutura organizacional de cada Secretaria de Estado, definida de acordo com a legislação que lhe é aplicada. [...]

SEÇÃO VII

Da Guarda Permanente de Documentos

Artigo 31 - São considerados documentos de guarda permanente:

I - os indicados nas Tabelas de Temporalidade de Documentos, que serão definitivamente preservados;

II - os de arquivos privados de pessoas físicas ou jurídicas declarados de interesse público e social, nos termos da lei;

III - todos os processos, expedientes e demais documentos produzidos, recebidos ou acumulados pelos órgãos da Administração Pública Estadual até o ano de 1940.

Como pode ser observado, diferentemente da legislação federal, a legislação estadual paulista não versa sobre a responsabilidade das diferentes instâncias de poder em relação aos seus arquivos, mas apenas determina a responsabilidade e o destino de documentos produzidos no âmbito da administração pública estadual, e não faz alusão aos documentos produzidos pelos legislativo e judiciário paulista.

Diante da necessidade de dar destino aos seus arquivos, o Tribunal de Justiça de São Paulo (TJSP), em 2009, através da Resolução 483 cria o Programa de Gestão de Documentos Arquivísticos. Em 2010, por meio do Provimento $n^{\circ} 1.743$, o TJSP estabelece normas e procedimentos para aplicação de seu programa de gestão de documentos:
Art. 140 Tribunal de Justiça poderá autorizar a entrega de processos classificados, avaliados e aptos para eliminação, às Universidades e Faculdades de Direito situadas no Estado de São Paulo, à Escola Paulista da Magistratura e a entidades de preservação histórica.

$\S 1^{\circ}$ Só se permitirá a entrega para fim de estudo e preservação histórica, hipóteses em que na capa do processo deverá conter a expressão, sob o carimbo: Documento de Propriedade do Poder Judiciário de São Paulo - Preservação Obrigatória.

$\S 2^{\circ} \mathrm{A}$ entidade depositária será responsável pela preservação dos processos, vedada a sua entrega a terceiros, podendo, contudo, devolvê-los à origem.

$\S 3^{\circ} \mathrm{A}$ entrega far-se-á mediante recibo circunstanciado, constando a Comarca, Vara, ano de distribuição, número do processo, natureza da ação e nome das partes, devendo o Ofício de Justiça ou o Arquivo Geral manter pasta onde os recibos serão colecionados.

$\S 4^{\circ}$ Fica vedada a entrega de processos que corram em segredo de justiça ou nos quais essa circunstância tenha sido declarada.

Mesmo com todas as normativas impostas pelas legislações federais e estaduais, tradicionalmente a prática de transferência de acervos é recorrente. Diversos fundos arquivísticos de origem do poder judiciário encontram-se em custódia do arquivo do executivo paulista há mais de um século e procedimentos de transferência de acervos continuam a serem feitas na atualidade. Apesar disso, conforme o apresentado, não é possível afirmar que as atuais levas de incorporações de acervo são feitas sob as mesmas condições legais que as de um século atrás.

Pela análise da legislação acima exposta, é possível perceber mudanças na forma de transmissão de acervos. Enquanto que os primeiros recolhimentos de documentos procedem de um decreto que determina que todos os documentos cartorários judiciais anteriores sejam recolhidos ao arquivo publico (Decreto $666 / 1899)$, sem que seu texto contemple outros detalhamentos ou especificações, os recolhimentos mais recentes são frutos de articulações políticas, norteados por responsabilidades mutuamente estabelecidas - como no termo de cooperação firmado em 29 de março de 2010, entre o APESP e o TJSP, cujo objeto pleiteia a transferência da guarda, preservação e restauro de autos de processos judiciais anteriores ao ano de 1940.

Tais procedimentos de transferência dessincronizada de documentação de um mesmo órgão produtor acabaram por gerar um "recorte físico" no arquivo da instituição, fazendo com que as partes do então arquivo dividido percorressem 
trajetórias arquivísticas distintas, sendo submetidos, consequentemente, a métodos de organização díspares que, por vezes, chegam a interferir na interpretação e aplicação do princípio de proveniência.

No caso específico do Juízo de Órfãos de São Paulo, é possível perceber tal situação: a documentação orfanológica recolhida até a primeira metade do século $X X$ foi identificada e referenciada como "Fundo Juízo dos Órfãos de São Paulo", com data-limite 1578-1926. Os documentos orfanológicos recolhidos a partir de 2010 foram identificados e referenciados como "Fundo Tribunal de Justiça de São Paulo", com data limite 1770-1890, e encontram-se mesclados a documentos procedentes de outras varas da Justiça (1).

Com o intuito de historizar a proveniência dessa massa documental, comentamos aqui que o Tribunal de Justiça de São Paulo é um órgão criado no final do século XIX, diante da reorganização judiciária propulsionada pela proclamação da República, em 1891. Originalmente, foi criado em 1874 recebendo o nome Tribunal da Relação de São Paulo e Paraná e possuía a função de tramitar e julgar processos em $2^{a}$ instância, assim como servir de arquivo para os processos decorrentes das diversas varas de $1^{\text {a }}$ instância de seu perímetro de atuação. Logo, o fato desse tribunal possuir documentos anteriores à década de 1874, deve-se mais a fatores de acumulação natural de arquivos do que à produção documental propriamente dita. Consideramos este um dado fundamental para discutir a relação existente entre custódia física, custódia legal e proveniência de um fundo.

\section{Custódia física e custódia legal de acervos}

Tradicionalmente, a idéia de custódia sobre um acervo arquivístico remete ao zelo pela documentação enquanto bem, englobando a responsabilidade pela preservação física, pelo acesso e, não raramente, o cuidado sobre o uso feito de seu conteúdo informacional, em termos legais.

$\mathrm{Na}$ atualidade, novas formas de custódia ganharam espaço e desvincularam a guarda do documento da propriedade sobre ele. A exemplo dessa tendência, Maria Luisa Conde Villaverde (2007), ao debater no seu artigo Un Aspecto de La Privatización de los Servicios Públicos sobre o processo de "externalización" da guarda arquivística —talvez cuja melhor tradução para o português seja terceirização-, apresenta a dinâmica do atual contexto político-econômico, afirmando que parte das causas motivadoras desse processo de "externalización" derivam da própria sociedade da informação, assim como também da influência direta do mundo das empresas privadas no modelo de "nova gestão pública".

Diante da atual conjuntura, é fundamental ter clara a diferença entre custódia física e custódia legal. Ligada a fins de preservação da integridade física dos documentos e à acessibilidade ao conjunto de informações neles registrados, cada vez mais a custódia física faz-se de forma independente da responsabilidade legal sobre a documentação. Em contrapartida, a custódia legal vincula-se à posse e à responsabilidade pela criação de políticas governamentais de acesso ao material, independentemente de sua localização física (Pearce-Moses, 2005).

Apesar da forte tendência de desvinculação, ainda hoje não é raro que as custódias físicas e legais andam emparelhadas, muitas vezes tendo seus conceitos mesclados. Evidentemente, que a custódia física de acervos implica necessariamente em responsabilidade jurídica, porém uma responsabilidade vinculada à garantia de guarda e proteção de arquivos, independentemente do vínculo de propriedade (cunha, 2008).

\section{Algumas considerações}

Diante do histórico acima relatado, pudemos identificar alguns possíveis fatores que motivaram a transferência de custódia, esquematizados no quadro que se segue:

\begin{tabular}{cc}
\hline Cedente & Receptor \\
\hline $\begin{array}{c}\text { problemas de } \\
\text { espaço }\end{array}$ & $\begin{array}{c}\text { preservação } \\
\text { da memória/patrimônio } \\
\text { documental }\end{array}$ \\
\hline $\begin{array}{c}\text { alto custo } \\
\text { do gerenciamento } \\
\text { do acervo }\end{array}$ & $\begin{array}{c}\text { incremento de seu próprio } \\
\text { acervo e/ou abertura de novas } \\
\text { linhas de atuação }\end{array}$ \\
\hline $\begin{array}{c}\text { implementação } \\
\text { de programas de } \\
\text { gestão documental }\end{array}$ & $\begin{array}{c}\text { fatores burocrático- } \\
\text { administrativos }\end{array}$ \\
\hline
\end{tabular}

Quadro I. Fatores motivadores

O que pudemos perceber, diante do processo de transferência de custódia de documentos, analisados à luz da legislação em vigor e dos fundamentos teóricos da arquivologia, é que tal movimentação de acervos, caso não sejam tomadas as devidas precauções, pode gerar problemas de cunho arquivísticos. Entre os problemas identificados no estudo de caso aqui mencionado, notamos claramente: 1) quebra do princípio de proveniência; 2) quebra do princípio de integridade arquivística; 3) mistura de fun- 
dos; e 4) necessidade da revisão do quadro de fundos da instituição receptora, no momento da incorporação do acervo.

Ante estas questões, evidencia-se a seriedade atrelada aos problemas de incorporação de acervos, posto que o que se encontra no cerne da discussão é o próprio princípio norteador da Arquivologia, o princípio da proveniência.

Apesar de universalmente aceito, o princípio da proveniência tem provocado mais problemas do ponto de vista de sua aplicação concreta do que de seu emprego teórico propriamente dito. Essa questão fica evidente quando analisamos os diversos recolhimentos do arquivo oriundo do Juízo de Órfãos de São Paulo, posto ser o histórico de custódia da documentação revelador dos percursos, desvios e paralelismos classificatórios de um mesmo fundo.

Ainda hoje se faz presente a constatação de Duchein (1986, p. 17), quando faz a seguinte afirmação:

A margem do respeito aos fundos todo trabalho arquivístico é arbitrário, subjetivo e desprovido de rigor.

No entanto, não é somente a opção pela não aplicação do princípio de proveniência que gera problemas de ordem arquivística. Conforme o verificado, interpretações dissonantes da procedência de documentos acarretam em fragmentação, quebra do vínculo orgânico e distorção da classificação arquivística.

Assim como Concepción Mendo Carmona (2004), entendemos ser necessário descender a história das instituições produtoras do documento para poder entender e aplicar efetivamente 0 princípio da proveniência, sendo que, para a correta aplicação do princípio, é essencial conhecer a estrutura da instituição produtora, seus métodos de funcionamento, seus procedimentos de trabalho e as variações que sofre ao longo do tempo.

Pearce-Moses (2005), ao discorrer sobre a utilidade do levantamento da história custodial de uma entidade, comenta que ela pode ser usada para descrever tanto a posse física quanto a intelectual do detentor do arquivo. Do mesmo modo, a história custodial também pode prover detalhes a respeito de mudanças de propriedade ou custódia que são significativas em termos do estabelecimento de autoridade, integridade e interpretação da massa documental.

Em conformidade com esta posição, acreditamos ser de fundamental importância o domínio de dados referentes à trajetória arquivística de um fundo, seja em relação aos distintos proces- sos de transferência ou recolhimento, seja em relação ao histórico de intervenções relativas à organização e preservação de documentos. Como resultado, a contextualização de documentos de arquivo - um dos principais objetivos da área- se dá de modo completo e íntegro, oferecendo ao usuário o acesso consubstanciado e integral à informação registrada.

\section{Notas}

(1) Para maiores detalhes sobre o recolhimento desse acervo, ver o Guia de Fundos do APESP. Nele é possível consultar as fichas de identificação, desenvolvidas de acordo com a Norma Brasileira de Descrição Arquivística (NOBRADE), na qual podem ser observadas as descrições dos fundos Juízo de Órfãos de São Paulo e Tribunal de Justiça de São Paulo, disponível em http://www.arquivoestado.sp.gov.br (02/10/2011).

\section{Referências}

APESP. Guia do Acervo. http://www.arquivoestado.sp.gov.br (02/10/2011).

APESP (1920-1999). Inventários e Testamentos. SP: Typ. Piratininga/IMESP. 47 vols.

Arquivo Nacional (Brasil) (1985). Fiscais e Meirinhos: a administração no Brasil Colonial. $2^{\mathrm{a}}$ ed. RJ: Arquivo Nacional/Nova Fronteir.

Conarq (Brasil). Legislação Arquivística Brasileira. http://www.conarq.arquivonacional.gov.br/ (13/02/2012).

Conde Villaverde, Maria Luisa (2007). Un Aspecto de La Privatización de los Servicios Públicos. Revista Arquivo \& Administração. RJ: AAB. 51-63

Cook, Terry. The Concept of the Archival Fonds in the PostCustodial Era: Theory, Problems and Solutions. // Archivaria. 35 (spring 1993).

Cunha, Murilo Bastos da; Cavalcanti, Cordélia Robalinho de Oliveira (2008). Dicionário de biblioteconomia e arquivologia. Brasília: Briquet de Lemos Livros.

Duchein, Michel (1982). O respeito aos fundos em Arquivística: princípios teóricos e problemas práticos. // Arquivo \& Administração. 10-14:1 (abr 1982-ago. 1986) 14-33.

Mendo Carmona, Concepción (2004). Consideraciones sobre el método em Archivística. // Documenta \& Instrumenta. 1 (2004) 35-46.

Pearce-Moses, Richard (2005). A Glossary of Archival and Records Terminology. SAA. http://www.archivists. org/glossary/index.asp (04/04/2012).

Poveda Velasco, Ignácio M. (2007). Os Esponsais no Direito Luso-Brasileiro. SP: Quartier Latin.

Ramalho, Joaquim Ignácio (1874). Instituições Orphanologicas. SP: Typ. de Jorge Seckler.

São Paulo. Coleção de Leis e Decretos do Estado de São Paulo, vários anos.

Troitiño, Sonia ("010). O Juízo de Órfãos de São Paulo: caracterização de tipos documentais (séc. XVI-XX). Tese (Doutorado em História Social). São Paulo: Faculdade de Filosofia, Letras e Ciências Humanas, Universidade de São Paulo, 2010. http://www.teses.usp.br/teses/ disponiveis/8/8138/tde-27042010-103207/.

TJSP. Regimento e Resoluções. http://www.tjsp.jus.br/Insti tucional/ (12/01/2012)

Enviado: 2012-05-15. Versión corregida: 2012-07-27. Aceptado: 2012-08-21. 
